\title{
Epidemio-Clinical Characteristics of Perinatal Anoxia and Immediate Outcome of Patients at Hospital Teaching Gabriel Touré of Bamako
}

\author{
L. N. Sidibé1,2*, H. Diall1, D. Konaté1,2, O. Coulibaly1, F. L. Diakité1,2, K. Sacko',2, F. Traoré1,2, \\ 0. H. Diallo1, L. Maïga1, I. Ahamadou1, I. Traoré1, I. Koné1, B. Maiga ${ }^{1,2}$, P. Togo ${ }^{1,2}$, \\ A. K. Doumbia1, A. Touré1, E. M. Cissé1, A. Dembélé1, Y. A. Coulibaly¹, A. Doumbia1, \\ A. Konaré1, A. A. Diakité1,2, B. Togo ${ }^{1,2}$, M. Sylla ${ }^{1,2}$, F. Dicko Traoré1,2 \\ ${ }^{1}$ Department of Pediatrics, CHU Gabriel Touré, Bamako, Mali \\ ${ }^{2}$ Faculty of Medicine and Odonto-Stomatology of Mali, Bamako, Mali \\ Email: *lalasidibe23@yahoo.fr
}

How to cite this paper: Sidibé, L.N., Diall, H., Konaté, D., Coulibaly, O., Diakité, F.L., Sacko, K., Traoré, F., Diallo, O.H., Maïga, L., Ahamadou, I., Traoré, I., Koné, I., Maiga, B., Togo, P., Doumbia, A.K., Touré, A., Cissé, E.M., Dembélé, A., Coulibaly, Y.A., Doumbia, A., Konaré, A., Diakité, A.A., Togo, B., Sylla, M. and Dicko Traoré, F. (2019) Epidemio-Clinical Characteristics of Perinatal Anoxia and Immediate Outcome of Patients at Hospital Teaching Gabriel Touré of Bamako. Open Journal of Pediatrics, 9, 326-336.

https://doi.org/10.4236/ojped.2019.94032

Received: October 22, 2019

Accepted: December 23, 2019

Published: December 26, 2019

Copyright $\odot 2019$ by author(s) and Scientific Research Publishing Inc. This work is licensed under the Creative Commons Attribution International License (CC BY 4.0).

http://creativecommons.org/licenses/by/4.0/

\section{(c) (i) Open Access}

\begin{abstract}
Introduction: Neonatal asphyxia (NA) is one of the most likely causes of neuro-developmental abnormalities in children. In Mali it is responsible for half of the early deaths and the third of neonatal mortality. Updated data would help understand and improve intervention strategies to reduce mortality. Objective: It is the study of epidemiological and clinical characteristics, the immediate outcome and the factors associated with newborn (NB) mortality with NA. Material and Methods: This was a prospective cross-sectional study from June $27^{\text {th }}$ to September $3^{\text {rd }} 2016$ about the NBs admitted for NA in the Hospital Teaching Gabriel Touré of Bamako. The clinical and biological data including the prognosis were collected from the health records of women, the liaison sheets and the medical file. The analysis was done using the software Epi info version 3.5.1. Results: 76 NBs were included which represented $23.45 \%$ of hospitalizations. The majority $(89.5 \%, \mathrm{n}=68)$ were admitted to less than 24 hours of life for NA grade III according to the Sarnat classification $(43.4 \%, \mathrm{n}=33)$. The average age of mothers was $24.17 \pm$ 5.5 years. Almost half $(41.3 \%, \mathrm{n}=31)$ were primigravida. The most common obstetrical event was dystocia $(64.5 \%, \mathrm{n}=49)$. The prognosis was poor in grade III anoxia in our patients (56\%) of deaths. Conclusion: The périnatal anoxia (PA) is a major health issue in Mali because of its frequency and severity. Monitoring of pregnancies, delivery assisted by skillful and qualified personnel, mastery of neonatal resuscitation techniques are good means of prevention.
\end{abstract}




\section{Keywords}

Anoxia, Newborn, Epidemiology, Clinical, Outcome

\section{Introduction}

Neonatal asphyxia is defined by the World Health Organization (WHO) as the failure to establish or initiate normal breathing at birth [1].

It is characterized by metabolic acidosis with an arterial $\mathrm{pH}$ of less than 7 and a basal deficit greater than or equal to $12 \mathrm{mmol} / \mathrm{L}$. Its occurrence is related to a severe alteration of uteroplacental gas exchange leading to fetal hypoxia and immediate respiratory acidosis and metabolic acidosis, reflecting an alteration of cellular metabolism. It combines clinical and biological criteria such as cardiorespiratory and neurological depression (APGAR score $<7$ in the fifth minute life) and evidence of acute hypoxia responsible for severe acidemia (arterial blood $\mathrm{pH}<7$ and/or baseline deficiency $\geq 12 \mathrm{mmol} / \mathrm{l}$ ) [2].

WHO estimates that four million children born with NA other the one hundred and thirty million births annually. Among them one million die, and nearly the same number survive with severe neurological sequelae [1]. NA is the third leading cause of neonatal mortality worldwide (23\%), after low birth weight (30\%) and neonatal infections (25\%) [1]. In the United States of America, the incidence is $6 \%$ o live births [3], while in Africa, its overall rate would be $42 \%$ o [4].

In Cameroon, the Demographic and Health Survey (DHS) in 2011 reported an incidence of $31 \%$ births [4]. In Burkina Faso, the intra-hospital incidence of perinatal anoxia (PA) was $19.8 \%$ [5]. In Mali, PA accounted for $42 \%$ of early neonatal mortality and $30 \%$ of the overall mortality [6].

The NA is one of the most likely causes of neuro-developmental abnormalities in children [7]. In France in 2009, Meau-Petit et al. pointed out that 40\% of motor disabilities of cerebral origin (MDCO) were attributable to cerebral anoxia [8]. In Cameroon, Mbonda et al. in 2010 observed that $43.68 \%$ of MDCOs were due to the NA; and these MDCOs were associated in $41.5 \%$ with epilepsy [9].

If the part of neonatal anoxia in neonatal mortality is known in Mali [6], however, its epidemio-clinical characteristics had never been studied before. This work, which is unique in this domain in Mali, will permit to understand perinatal anoxia in Mali and to improve its management.

The objective of this work is to study the epidemiological and clinical characteristics of PA, as well as the immediate outcome of newborns included.

\section{Material and Methods}

This was a cross-sectional prospective study, which was conducted from June $27^{\text {th }}$ to September $3^{\text {rd }}, 2016$ in the neonatology department of the Hospital Teaching Gabriel Touré of Bamako. This structure is the top referral level in the 
health pyramid of Mali, and receives referred patients from other sanitary structures in the country.

It had included all neonates from 0 to 72 hours of life who have been hospitalized for NA for at least 37 weeks.

The diagnosis of neonatal asphyxia was essentially based on clinical criteria: neurological abnormalities at birth, an APGAR score $<7$ at 5 minutes of life and a neonatal resuscitation at birth.

The severity of asphyxia was measured according to the classification of SARNAT (SARNAT I, II, III) [10]:

- Grade I or minor encephalopathy with resolved moderate hypotonia and hyperexcitability in less than 48 hours;

- Grade II or moderate encephalopathy leading to convulsions, impairment of consciousness, tone and abnormal movements as well;

- Grade III or severe encephalopathy corresponding to a deep coma with loss of brainstem reflexes.

Neonatal infection was defined from the following arguments:

- Anamnestic: maternal fever per partum, stained amniotic fluid, prolonged rupture of membranes for more than 12 hours, chorioamnionitis;

- Clinics: refusal of suckling, digestive disorders, thermal instability, apnea-bradycardia-desaturations syndrome, respiratory distress, tachycardia;

- Biological: Increase of C-Reactive Protein (CRP) above $20 \mathrm{mg} / \mathrm{L}$, signs of infection on Complete blood count (CBC); to bacteriological by the positivity of the blood culture.

Respiratory distress was diagnosed: in the presence of signs of respiratory control, apnea, tachypnea with respiratory rate above 60 cycles per minute, bradypnea under 30 cycles per minute.

The parameters studied were:

- The mother's data: age, parity, gravidity, level of schooling, occupation, obstetric events prior and post partum.

- Newborn data: the term, the chronological age, the sex, the course of delivery, APGAR, the resuscitation, clinical and biological data, transfer.

The data were collected from the pregnancy monitoring records, the liaison sheets in the case of transfer, from the parents/caregivers and the medical register.

This study was conducted in accordance with the ethical principles of Health Act of Mali concerning research. Permission to conduct the study was granted by the local research committee of our institution. Parents' informed consent was obtained before the inclusion of newborns.

The collected data was recorded and analyzed with the software Epi info version 3.5.1. The statistical tests of Chi squared student were used to compare the qualitative results, the significance level was less than 0.05 .

\section{Results}

Out of 324 hospitalized newborns hospitalized during the study period, 76 were 
for a PA, or $23.45 \%$. There were 50 male newborns (66\%) and 26 females (34\%), a sex ratio of 1.94 . The majority, 68 newborns were admitted in less than 24 hours of life (89.5\%), the average weight was $2876 \pm 689 \mathrm{~g}$ with extremes (1600 and $4000 \mathrm{~g}$ ), the average height was $50 \pm 2.9 \mathrm{~cm}$ with extremes $(43$ and $58 \mathrm{~cm}$ ), the cranial perimeter was $34.11 \pm 1.8 \mathrm{~cm}$ with extremes $(29$ and $38 \mathrm{~cm})$. The majority of newborns were referred (78.5\%), those of CHU Gabriel Toure maternity unit accounted for (18.9\%) and those who come by themselves were (2.6\%).

Women were aged on average $24.17 \pm 5.5$ years old with extremes (16 and 44 years). $30.3 \%(\mathrm{n}=23)$ were between 16 and 20 years old, $68.4 \%(\mathrm{n}=52)$ between 21 and 35 years old, and $1.3 \%(\mathrm{n}=1)$ between 36 and 44 years old. Almost half of the mothers $(46 \%)$ were in school, the majority (77.6\%) were housewives. 48.6\% $(\mathrm{n}=37)$ were primiparous, $31.6 \%(\mathrm{n}=24)$ multiparous, $19.8 \%(\mathrm{n}=15)$, pauciparous, $41.3 \%(\mathrm{n}=31)$ primigravidity, $33.3 \%(\mathrm{n}=25)$ paucigravidity and $25.4 \%(\mathrm{n}=19)$ multigravidity.

$45.4 \%$ of the mothers had performed more than 3 antenatal consultations (ANC), 49.3\% between 1 to 3 ANC and 5.3\% $(n=4)$ no ANC. Most deliveries 98.7\% $(\mathrm{n}=75)$ were done at a health center and $1.3 \%(\mathrm{n}=1)$ at home. The most common obstetric events were dystocia $64.5 \%(\mathrm{n}=49)$, eclampsia, and term excess $3.9 \%(n=3)$. In $76 \%$ of the cases, vaginal delivery was the most common $(\mathrm{n}=58)$, of which $3 \%$ with forceps use and $6 \%$ with the suction cup. Caesarian sections accounted for $24 \%(\mathrm{n}=18)$. The amniotic fluid was meconium-stained in $35.5 \%$ of cases $(n=27)$, unclear $34.2 \%(n=26)$ and clear $30.3 \%(n=23)$. The Apgar score was between 4 and 7 in 35 neonates (46.1\%) at the first minute of life, and 8 newborns $(10.5 \%)$ at the $5^{\text {th }}$ minute. Resuscitation procedures were performed in $58(75.7 \%)$ newborns at birth and not performed in 18 (24.3\%).

The symptoms at admission are shown in Table 1 . They were most often the abnormalities of archaic reflexes (86.8\%) followed by the respiratory troubles (81.6\%) then the troubles of tonus (64.5\%) hemodynamics (52.6\%). According to Sarnat's classification, $18.4 \%$ of neonates $(\mathrm{n}=14)$ were in stage I, $28.2 \%(\mathrm{n}=$ $29)$ in stage II and $43.4 \%(\mathrm{n}=33)$ in stage III (Figure 1$)$.

The blood count has revealed leukopenia in 48 neonates (84.2\%), thrombocytosis in 9 (15.8\%) and hypoglycemia in 5 (6.6\%).

Biological infectious analysis demonstrated CRP above standar in 8 (13.3\%). Blood culture was positive in $11(14.5 \%)$ in these cases, Staphylococcus aureus was the most common germ $(n=6[7.9 \%])$.

Cranial ultrasonography performed in 24 neonates $(31.6 \%)$ was normal in most cases $79.2 \%$, however an increase in the index of resistance of the cerebral artery was observed in 4 cases.

The average hospital stay was 5.6 days with extremes ranging from ( 1 and 16 days). The outcome at discharge was favorable in 51 patients $(67.1 \%)$. We have recorded 25 deaths (32.9\%).

The evolution according to the stage of encephalopathy and the score relationship of Sarnat-Death is recorded in (Figure 2). 


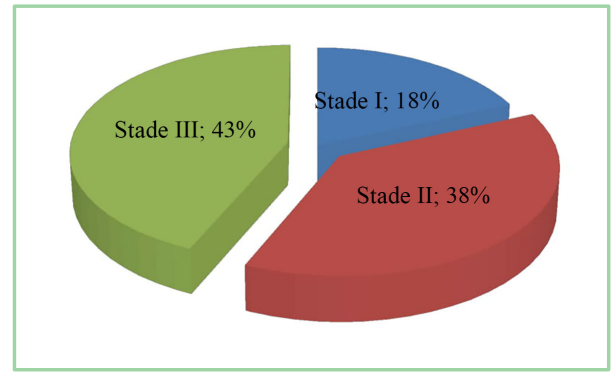

Figure 1. Distribution of newborns according to the encephalopathy stage of Sarnat.

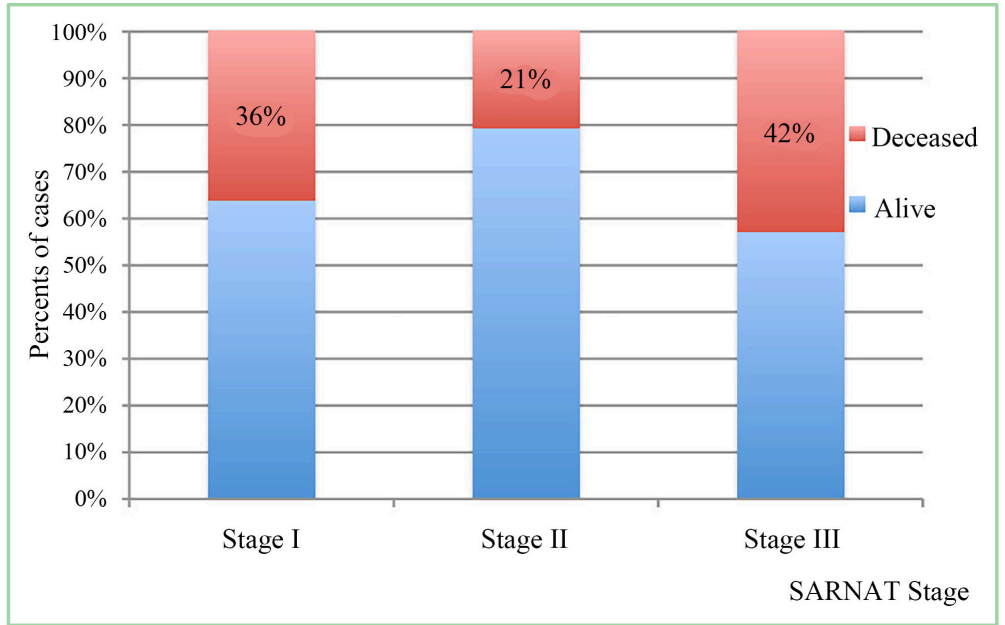

Figure 2. Neonatal outcome according to encephalopathy SARNAT stage.

Table 1. Distribution of newborns according to examination signs.

\begin{tabular}{ccc}
\hline Examination signs & Numbers & Percentages (\%) \\
\hline Anomalies of primary reflexes & 66 & 86.8 \\
Respiratory & 62 & 81.6 \\
Tone disorders & 49 & 64.5 \\
Hemodynamic & 40 & 52.6 \\
Convulsions & 10 & 13.2 \\
Digestives & 3 & 3.9 \\
Cutaneous & 2 & 2.6 \\
\hline
\end{tabular}

\section{Discussion}

Perinatal asphyxia is a relatively frequent situation, which is serious because of the cerebral pain it causes. It is one of the most common causes of neuro-developmental abnormalities in children [11] and a leading cause of death [12].

The PA may result in multi-visceral failure or anoxic-ischemic encephalopathy (AIE) [13]. In 2010, of the 7.6 million deaths of children under 5, 40.3\% occurred during the neonatal period. Prematurity, complications of childbirth in- 
cluding PA and infections were the leading causes of neonatal death [14]. In Cameroon, in 2011 the Demographic and Health Survey (DHS) reported an incidence of $31 \%$ births with PA [4].

In our series, over 324 neonates hospitalized during the study period, 76 were suffering from PA, or $23.45 \%$. Our result is close to those of Danièle, K.K. et al. in Cameroon and Halloran, R. et al. in Zambia, who have found out respectively (22.9\%) and (23\%) PA cases [8] [15], but higher than those figured out by Ouedraogo, S.O. in Burkina (19.8\%), Okoko, A.R. in Brazzaville (15.6\%) [6] [16]. Lower rates were found in Nigeria by Ige et al. in 2011 (12.6\%) and West et al. in 2013 (6.3\%), in Cameroon Chiabi et al. in 2010 (8\%) [13] [17] [18] and in Benin by Almeida, M. et al. in 2017 (4.5\%) [19]. The disparities between these different rates can be accounted for by the size of the study populations but particularly by the criteria used to define PA.

In our series the average weight of newborns was $2876 \pm 689 \mathrm{~g}$ and the most represented group was between 2500 and 3999 g. In Nigeria in 2013, a study on the PA found an average weight of $3000 \pm 900 \mathrm{~g}$. In Yaoundé, Cameroon, Chelo et al. found that newborns with birth weight $\geq 2500 \mathrm{~g}$ accounted for $94.3 \%$ of the sample size [20], Danièle K.K. et al. had found an average weight of $3086 \pm 625 \mathrm{~g}$ and the most represented group was between 2500 and $4000 \mathrm{~g}$ [8]. In our series the male predominance is substantial with $66 \%$ (sex ratio: 1.9). This result is similar in all the studies we have gone through [6] [8]. According to Badawi [21], male sex increases the risk of perinatal asphyxia by $50 \%$. Johnston reports that sex hormones, including estrogen, would be protective against anoxic-ischemic lésions [22].

The young age of mothers, age group or fertility rate was highest and primiparity was significantly associated with the PA. Because of their inexperience, they would tend to be less able to monitor their pregnancy [19]. In our series, the mean age of mothers was $24.17 \pm 5.5$ years with extremes (16 and 44 years), near half of our mothers $48.6 \%(n=37)$ were primiparous. A maternal age under 25 was also found by Aslam et al. in Pakistan in 2012 [23]. Rehana et al. in India, on the other hand, found that Asphyxia increased with maternal age $>35$ years [24].

The WHO recommends a minimum of 4 ANC for the proper monitoring of pregnancies. The 4 repositioned ANC must be well planned over time with specific objectives. They enable not only the prevention, detection and early treatment of complications, but also the preparation of childbirth and the promotion of health [25]. Additional consultation may be required in case of complications or specific need for control.

In our study, mothers performed more than 3 ANC in $45.4 \%, 1$ to 3 in $49.3 \%$ and no ANC in 5.3\% (4 mothers). These results are lower than those reported by Ouédrago, S.O. (92.9\%), Danièle, K.K. (86\%) and Okoko, A.R. (80.8\%) [6] [16] [17]. In our series a large number of women did not perform the minimum number of ANC recommended by WHO. Nearly half of the mothers $48.6 \%$ ( $\mathrm{n}=$ 
37) were primiparous, therefore inexperienced and have little or no knowledge about the signs of danger that could affect the prognosis of their future newborn.

The low frequentation of health facilities during pregnancy in our study can be explained by the illiteracy of mothers (54\%), the difficult socio-economic conditions and the absence of a generalized health insurance system.

Capacity building for obstetricians and midwives to improve the quality of pregnancy monitoring and delivery management are key levers for preventing PAs. In our study more than half of newborns $76 \%(\mathrm{n}=58)$ were born vaginally, among which $9 \%$ by instrumental low way (forceps $3 \%$, suction cup 6\%). Caesarean birth accounted for $24 \%(n=18)$. This rate of caesarean section is comparable to the rate obtained by a Congolese study (25.9\%) [16], but higher than that found by Daniel, K.K. et al., Cameroon (18.6\%) [8]. The vaginal delivery was not a risk factor in the study in Benin, unlike cesarean delivery [19].

Postnatal neurological assessment is fundamental because the importance and duration of neurological signs are the best long-term prognostic criteria. In our study, clinical symptomatology was dominated by neurological signs (94.7\%), followed by respiratory and hemodynamic signs with $81.6 \%$ and $52.6 \%$, respectively. Neurological signs frequently found were disruption of archaic reflexes (86.8\%), hypotonia (57.9\%) and convulsion (13.2\%). In the series of Ouedrago S.O. et al. the main neurological manifestations pointed out were archaic reflex anomalies (92.9\%), hypotonia (88.2\%) and convulsions (35.3\%) [6]. This observation is noticed by many other African authors [16].

Neonatal resuscitation is an important intervention to improve the prognosis of children with NA. Depending on the time of prenatal asphyxia, per natal or post natal, the causal pathology, the time of the beginning of resuscitation, the technical platform, neonatal resuscitation may be effective or not to prevent complications in children. In our study resuscitation at birth involved $75.7 \%$ of newborns, the average duration was 16.6 minutes with extremes of $(5 \mathrm{mn}$ and 30 $\mathrm{mn}$ ). In the series of Ouedrago S.O. et al., resuscitation concerned all newborns at birth with an average duration of ten minutes [6]. In Congo, Okoko A.R. et al. found out an average duration of 4.3 minutes with extremes of ( $1 \mathrm{~min}$ and 26 $\mathrm{mn})$, in $62.5 \%$ [16].

Perinatal asphyxia is responsible for poor adaptation to ectopic life with an Apgar score $<7$ in the fifth minute, but this sign is not specific. This score makes it possible to assess the immediate adaptation of the newborn at birth [6] [26]. A child with an Apgar score $\geq 7$ at 5 minutes of life got adapted well. The Apgar rating, a simple and available descriptive element, is the indispensable tool for diagnosing PA in Africa. In view of these advantages, the rating of the Apgar score should not be neglected by healthcare providers [6] [26]. In our study Apgar score was not made in nearly half of newborns. In $24 \%$ of cases it was less than 7 in the 5th minute. This result is lower than that of Danièle, K.K. in Cameroon $64 \%$ [6]. It suggests that $76 \%$ of our newborns with a PA had an Apgar score at birth that did not reflect central nervous system depression.

Most newborns with a score below 4 to 5 minutes developed encephalopathy, 
14\% for those with an Apgar score between 4 and 6. It should be noted that a low Apgar score of 5 minutes is correlated to the immediate future of the child (risk of encephalopathy) but this score has a rather low prognostic value for long-term outcome [12].

The neonatal encephalopathy testifies in case of asphyxia of the cerebral anoxia. The most widely used clinical and prognostic classification is Sarnat classified in three grades. Grade I: corresponds to a minor encephalopathy, with moderate hypotonia and hyperexcitability resolved in less than 48 hours, grade II or moderate encephalopathy is manifested by disorders of consciousness, tone, abnormal movements and often convulsions. The prognosis is reserved with $40 \%$ to $60 \%$ of sequelae. Grade III or severe encephalopathy is marked by deep coma and often loss of trunk reflexes. The prognosis is pejorative with almost certain evolution towards death or serious neurological sequelae [12]. In our series, grade I represented $19 \%$, grade II $38 \%$ and grade III $43 \%$, so most of our patients had the severe form.

In terms of prognosis, the PA in our study is characterized by the high rate of severe form $43 \%$ and death at $32.9 \%$, this rate is close to that of Bisselete, $\mathrm{T}$. in the Congo [26]. Ouédraogo, S.O. et al., Danièle, K.K. and Azoumah found out lower rates with respectively $21.3 \%, 10.8 \%$ and $7.1 \%$ [6] [8] [27]. Ige et al. had $58 \%$ favorable and $28 \%$ fatal [17]. In the study of Padayachee et al. $88 \%$ of newborns evolved favorably [28].

The management of the NA includes several aspects such as: medication management, a good hydro-electrolyte balance, the correction of metabolic disorders, respiratory assistance, parenteral nutrition and even therapeutic hypothermia may be necessary [29]. This management can only be done on the basis of significant clinical, biological and neuroradiological monitoring. In our context, the means of treatment and surveillance remain very limited hence the high mortality. Prevention therefore remains an essential element. It involves well-monitored ACs, adequate fetal monitoring, early management of the NA and the mastery of neonatal resuscitation techniques in the delivery room [8].

Beyond its high mortality, the NA is one of the most likely pathologies of neuro-developmental sequelae in children [11]. The spectrum of these developmental abnormalities is large and can be evaluated by several scores among them Denver score [30]. The Denver score allows health professionals to assess the development of children's psychomotor skills between birth and 6 years old.

This study was a prospective study about perinatal anoxia and included only newborns who met the clinical criteria of perinatal asphyxia that is the Apgar score. The non-availability of $\mathrm{PH}$ in the cord and basic defict in our structure has not permitted us to master these parameters in our patients. That could, in fact, make the number of diagnosed infra-clinical cases underestimate in our cohort. New studies, taking also into account, the biological criteria of anoxia, could fill up this gap of selection. 


\section{Conclusion}

The PNA is a public health issue in Bamako because of its frequency and severity as shown by the high morbidity and mortality observed in the neonatology unit. In a context of low resources, it is necessary to focus on prevention by monitoring pregnancies, delivery assisted by skillful personnel, mastery of neonatal resuscitation techniques in the delivery room. The evolution of PA is closely related to the severity of encephalopathy.

\section{Acknowledgements}

We thank all patients and their families who participated in this study, the staff of the department of the Hospital Teaching Gabriel Touré who helped to carry out this work, the authors for proofreading and correction and finally the scientific committee of the journal which allows the diffusion of our results.

\section{Conflicts of Interest}

The authors declare no conflicts of interest regarding the publication of this paper.

\section{References}

[1] WHO (2012) Guidelines on Basic Newborn Resuscitation [Internet].

[2] MacLennan, A. (1999) A Template for Defining a Causal Relation between Acute Intrapartum Events and Cerebral Palsy: International Consensus Statement. British Medical Journal, 319, 1054. https://doi.org/10.1136/bmj.319.7216.1054

[3] Levene, M.L., Kornberg, J. and Williams, T.H.C. (1985) The Incidence and Severity of Post-Asphyxial Encephalopathy in Full-Term Infants. Early Human Development, 11, 21-26. https://doi.org/10.1016/0378-3782(85)90115-X

[4] Institut National de la Statistique (INS) and ICF International (2012) Enquête Démographique et de Santé et indicateurs Multiples du Cameroun 2011. INS et ICF International, Calverton.

[5] Bordarier, C. and Farhat, M. (1998) Souffrance cérébrale asphyxique du nouveau-né à terme. EMC pédiatrie-maladies infectieuses. Elsevier Masson SAS, [4-002-S-60], $1-36$.

[6] Ouedraogo Yugbare, S.O., Coulibaly, G., Koueta, F., et al. (2015) Profil à risque et pronostic néonatal de l'asphyxie périnatale en milieu hospitalier pédiatrique à Ouagadougou. Journal de Pédiatrie et de Puériculture, 28, 64-70. https://doi.org/10.1016/j.jpp.2015.02.003

[7] Sidibé, T., Sangho, H., Doumbia, S., et al. (2006) Mortalité néonatale dans le district sanitaire de Kolokani (Mali). Journal de Pédiatrie et de Puériculture, 19, 272-276. https://doi.org/10.1016/j.jpp.2006.08.004

[8] Koum, D.K., Essomba, N., Penda, C.I., et al. (2018) Evolution of Newborns with Neonatal Asphyxia at the Bonassama District Hospital. The Journal of Medicine and Health Sciences, 19, 50-55.

[9] Meau-Petit, V., Tasseau, A., Lebail, F., et al. (2010) Hypothermie contrôlée du nouveau-né à terme après asphyxie périnatale. Archives de Pédiatrie, 17, 282-289. https://doi.org/10.1016/j.arcped.2009.10.030 
[10] Mbonda, E., Nguefack, S., Chiabi, A., et al. (2011) Epilepsie chez les enfants atteints d'infirmité motrice cérébrale:A propos de 412 observations à Yaoundé, Cameroun. Clinics in Mother and Child Health, 8, 1-5. https://doi.org/10.4303/cmch/C110801

[11] Messaouda, H. (2012) Dépistage et prise en charge du handicap d'origine périnatale: Exemple de l'asphyxie néonatale. Forum International Handicap Mental en Méditerranée.

http://www.santesud.org/sinformer/evenements/autres/Presentation_ppt_PrHaridi. pdf

[12] Al Kadaoui, N. and Barkat, A. (2018) L'asphyxie périnatale au centre de médecine et de réanimation néonatales-FMP Rabat. Centre de médecine et de réanimation néonatales-faculté de médecine et de pharmacie Rabat-Université Mohamed V. EPH-International Journal of Medical and Health Science, 4, 2456-6063.

[13] Chiabi, A., Nguefack, S., Mah, E., et al. (2013) Risk Factors for Birth Asphyxia in an Urban Health Facility in Cameroon. Iranian Journal of Child Neurology, 7, 46-54.

[14] Liu, L., Johnson, H.L., Cousens, S., et al. (2012) Global, Regional, and National Causes of Child Mortality: An Updated Systematic Analysis for 2010 with Time Trends since 2000. The Lancet, 379, 215-261. https://doi.org/10.1016/S0140-6736(12)60560-1

[15] Halloran, D.R., McClure, E., Chakraborty, H., et al. (2009) Birth Asphyxia Survivors in a Developing Country. Journal of Perinatology, 29, 243-249. https://doi.org/10.1038/jp.2008.192

[16] Okoko, A.R., Ekouya-Bowassa, G., Moyen, E., et al. (2016) Moyen, Asphyxie périnatale au centre hospitalier et universitaire de Brazzaville. Journal de Pédiatrie et de Puériculture, 29, 295-300. https://doi.org/10.1016/j.jpp.2016.09.003

[17] Ige, O.O., Adah, R.O., Ekere, I.A., et al. (2013) Risk Factors and Mortality of Severely Asphyxiated Neonates in a Tertiary Center in North-Central Nigeria. Jos Journal of Medicine, 7, 10-14.

[18] West, B.A. and Opara, P.I. (2013) Perinatal Asphyxia in a Specialist Hospital in Port Harcourt, Nigeria. Nigerian Journal of Paediatrics, 40, 206-210.

[19] Almeida, M., Lalya, F., Bagnan, L., et al. (2017) Asphyxie périnatale du nouveau-né à terme: Facteurs de risque et pronostic au Centre National Hospitalier et Universitaire (CNHU-HKM) de Cotonou. Journal Africain de Pédiatrie et de Génétique Médicale, 1, 10-15.

[20] Chelo, D., Monebenimp, F., Npanguepko, F.R.T., et al. (2012) Mortalité néonatale précoce et ses déterminants dans une maternité de niveau I à Yaoundé, Cameroun. Pan African Medical Journal, 13, 67. https://www.ncbi.nlm.nih.gov/pmc/articles/PMC3549444

[21] Badawi, N., Kurinczuk, J.J., Keogh, J.M., et al. (1998) Antepartum Risk Factors for Newborn Encephalopathy: The Western Australian Case-Control Study. BMJ, 317, 1549-1553. https://doi.org/10.1136/bmj.317.7172.1549

[22] Johnston, M.V. and Hagberg, H. (2007) Sex and Pathogenesis of Cerebral Palsy. Developmental Medicine \& Child Neurology, 49, 74-78. https://doi.org/10.1017/S0012162207000199.x

[23] Aslam, H.M., Saleem, S., Afzal, R., et al. (2014) Risk Factors of Birth Asphyxia. Italian Journal of Pediatrics, 40, 94. https://doi.org/10.1186/s13052-014-0094-2

[24] Rehana, M., Yasmeen, M., Farrukh, M., et al. (2007) Risks Factors of Birth Asphyxia. JAMC, 19, 67-71. https://doi.org/10.1080/09503110601138027

[25] Daouda Yaya, K. (2010) Consultation prénatale recentrée: perception des gestantes 
et des accouchées récentes au Centre de Santé de référence de Kolondieba. Thèse de médecine, Faculté de Médecine de Bamako, Mali.

[26] Bisselele, T., Naulaers, G., Bunga Muntu, P., et al. (2013) A Descriptive Study of Perinatal Asphyxia at the University Hospital of Kinshasa (Democratic Republic of Congo). Journal of Tropical Pediatrics, 59, 274-279.

https://doi.org/10.1093/tropej/fmt011

[27] Azoumah, K.D., Balaka, B. and Aboubakari, A.S. (2010) Morbidité et mortalité néonatales au CHU de Kara (Togo). Medecine d Afrique Noire, 57, 109-112.

[28] Padayachee, N. and Ballot, D.E. (2013) Outcomes of Neonates with Perinatal Asphyxia at a Tertiary Academic Hospital in Johannesburg, South Africa. SAJCH, 7, 89-94. https://doi.org/10.7196/sajch.574

[29] Truttmann, A. and Hagmann, C. (2012) Prise en charge de l'encéphalopathie hypoxique-ischémique du nouveau-né à terme: Hypothermie thérapeutique et création d'un registre national de l'asphyxie néonatale. Paediatrica, 23, 25-28.

[30] Leroy-Malherbe, V. (2002) Déficiences motrices et situations de handicaps [Internet]. 2è édition, APF, Paris. 